\title{
Peranan Knowledge Management dalam Meningkatkan Keunggulan Kompetitif BTPN Syariah
}

\author{
Anggiearanidipta Suma Muhammadsjah ${ }^{\circledR}$ \\ ${ }^{1}$ Menara BTPN, CBD Mega Kuningan, Jakarta, Indonesia. \\ DOI: https://doi.org/10.21009/JPI.o12.06
}

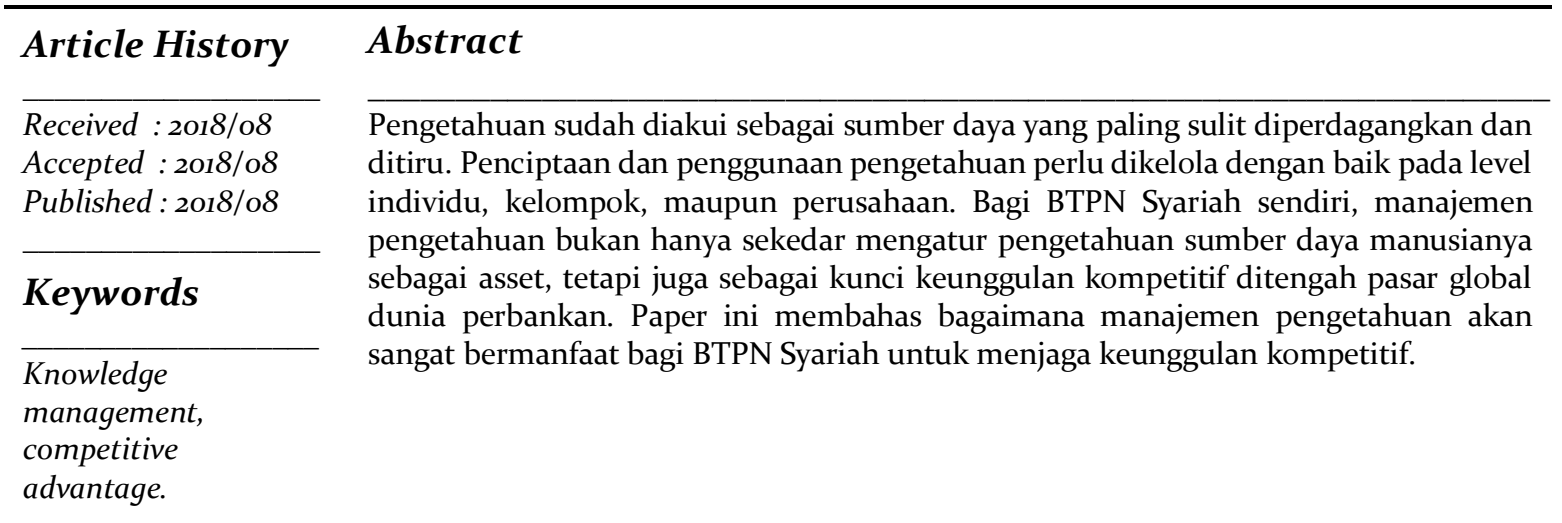

\begin{abstract}
Knowledge has been recognized as the most difficult resource traded and imitated. The creation and use of knowledge needs to be managed at the level of individuals, groups, and companies. For the Bank itself, knowledge management is not organizing knowledge of their human resources as assets, but also as a key competitive advantage amid the global banking market. This paper discusses how knowledge management will be very beneficial for the BTPN Sharia to maintain a competitive advantage.
\end{abstract}




\section{PENDAHULUAN}

Tantangan besar saat ini dirasakan berbagai perusahaan dan organisasi untuk bersaing dalam pasar global, dimana seluruh penilaian atas produk dan pelayanan diserahkan kepada pasar. Produk dan pelayanan yang terlihat dan dirasakan secara langsung oleh pasar menjadi pembeda antara perusahaan yang satu dengan yang lain. Pasar pun saat ini semakin selektif dalam memilih produk. Di tengah pesatnya informasi yang berkembang, pasar tidak lagi menilai berdasarkan apa yang mereka lihat dan rasakan, tetapi juga nilai-nilai yang muncul dari produk tersebut.

The Body Shop misalnya, muncul dengan nilai-nilai social anti uji coba kosmetik terhadap hewan, program Community Trade ${ }^{1}$, program lingkungan, dan program-program social lainnya. Community Trade, sebuah konsep membangun komunitas lokal di sekitar wilayah operasi rantai pasokan The Body Shop. The Body Shop pertama dimulai pada tahun 1987 dengan membangun sebuah komunitas kecil di India Selatan, yang terus menjadi pemasok kunci hingga hari ini.

Sejak itu The Body Shop terus membangun kemitraan dengan komunitaskomunitas di lebih dari 20 negara yang seringkali dianggap kecil atau diremehkan baik oleh masyarakat lokal sendiri maupun oleh perusahaan lain. Semangat The Body Shop menjalankan bisnisnya adalah "we believe business can be both profitable and responsible" (Kusumawati 2009). The Body Shop menjadi contoh bagaimana values dan beliefs sebuah perusahaan membedakannya dengan kompetitor lain.

Perusahaan-perusahaan perbankan sendiri menjadikan nilai-nilai sebagai pembeda dan basis pelayanan yang diberikan kepada pelanggannya. Di BTPN Syariah, misi untuk memberdayakan mass market ${ }^{2}$ sudah melebur dengan nilai-nilai yang ada. Nilai-nilai yang ada pada sebuah perusahaan selain menjadi pembeda, juga menjadi keunggulan kompetitif. Beberapa organisasi menciptakan dan mengeksploitasi keunggulan kompetitif melalui merger, akuisisi, perekanan strategic, dan pemasok, dan peningkatan saluran distribusi (Hamel dan Prahalad dalam Longenecker, Clinton O;Ariss, Sonny S, 2002, h. 640). Begitupun yang dilakukan BTPN Syariah. BTPN Syariah merupakan hasil merger Unit Usaha Syariah BTPN dengan Bank Sahabat Purbadanarta. Kedua bagian ini memiliki visi misi yang hampir serupa. Keunggulan kompetitif berusaha dieksploitasi dengan proses merger ini.

Keunggulan kompetitif menjadi semakin bernilai bagi perusahaan ketika dihadapkan pada kebutuhan untuk memenuhi harapan pasar dan berkompetisi pada saat yang bersamaan. Sebagai salah satu perusahaan perbankan yang sedang berkembang, BTPN Syariah perlu menggali lebih dalam keunggulan kompetitifnya agar dapat bertahan dalam persaingan global. Terdapat berbagai cara untuk meningkatkan keunggulan kompetitif, tergantung dari sisi mana dan bagaimana keunggulan kompetitif tersebut dilihat. Paper ini akan menjawab bagaimana keunggulan kompetitif ini dipandang, dan dengan pendekatan knowledge management, bagaimana keunggulan kompetitif di BTPN Syariah dapat diraih.

\section{Pengetahuan}

Sebagaimana yang diutarakan oleh Shehabat, Mahdi, dan Khoualdi (2008, h.206), pengetahuan berasal dari data dan informasi. Data merepresentasikan observasi atau fakta diluar konteks tertentu, biasanya tidak memiliki makna. Sementara itu, informasi merupakan hasil penempatan data dalam beberapa konteks yang memiliki makna. Sedangkan pengetahuan adalah apa yang kita percayai berdasarkan akumulasi informasi yang bermakna melalui pengalaman tertentu, komunikasi, dan inferensi. Akumulasi informasi yang bermakna selalu ada di dalam perusahaan atau organisasi. Sayangnya sebagai asset yang tidak tampak, manajemen pengetahuan kadang dilupakan dan bukan prioritas.

Seperti asset perusahaan lainnya, proses penciptaan dan transfer pengetahuan harus dikelola dengan wawasan yang lebih signifikan agar investasi pengetahuan ini lebih bernilai.

\footnotetext{
${ }^{1}$ Community Trade, sebuah konsep membangun komunitas lokal di sekitar wilayah operasi rantai pasokan The Body Shop.
}

\footnotetext{
${ }^{2}$ Yang dimaksud Mass Market adalah segmen masyarakat berpenghasilan rendah dan segmen usaha mikro dan kecil
} 
(Bhagat, Kedia, Harveston, \& Triandis, 2002 h. 2). Seperti yang sudah disinggung sebelumnya, pengetahuan yang bernilai bagi organisasi atau perusahaan tentunya harus dapat dikelola dengan baik. Kebermanfaatannya sangat bergantung dari bagaimana pengetahuan tersebut dikelola.

Pengetahuan dari level individu, grup dan organisasi; berasal dari informasi; ditafsirkan dan digunakan pada tiga tingkatan, dibuat melalui proses manusia yang berbeda yang melibatkan faktor-faktor sosial, situasional, budaya, dan kelembagaan, memanfaatkan kontinjensi intelektual dan sosial yang memikirkan perpaduan, komunikasi, dan perilaku orang-orang; dan mengarah pada tindakan tertentu (Martins dan Martins 2011, h. 52-53).

Konsep pengetahuan yang diuraikan oleh Martins dan Martins di atas memberikan gambaran secara utuh pada level apa saja pengetahuan berada, bagaimana pengetahuan dibuat; dan tindakan tertentu yang dihasilkan dari pengetahuan tersebut.

\section{Keunggulan Kompetitif}

Uyterhoeven, Ackerman, dan Rosenblum (1973) serta Hofer and Schendel (1978) dalam Mooney (2007, h. 111), mengungkapkan keunggulan kompetitif sebagai cara dimana perusahaan menerapkan keterampilan dan sumber daya untuk produk individual atau pasar. Sedangkan Porter (1985) menyebutkan keunggulan kompetitif merujuk pada faktor organisasional yang memungkinkan perusahaan untuk mengungguli para pesaingnya.

Keterampilan dan sumber daya yang disebutkan di atas dapat kita simpulkan sebagai salah satu pengetahuan yang dimiliki karyawannya. Tujuan yang ingin diraih tidak lain adalah untuk mengungguli para pesaing yang ada.

Akuisisi pengetahuan telah menjadi sumber daya penting untuk menciptakan dan mempertahankan keunggulan kompetitif. (Hitt, Ireland, \& Lee, 2000, h. 231-246). Sayangnya belum semua perusahaan memahami hal ini. Keunggulan kompetitif sering kali dipandang sebagai suatu hal yang dapat dibangun dari produk dan pelayanan yang baik kepada pelanggan atau pihak luar dari sebuah organisasi.
Sebagaimana Grant (2001, h.118) menggambarkan hubungan antara sumber daya dan keuntungan, dan menempatkan keunggulan kompetitif berasal dari keuntungan biaya dan keuntungan atas diferensiasi produk. Keuntungan atas diferensiasi produk digambarkan seperti merek; teknologi produk; marketing, distribusi, dan kemampuan pelayanan. Akuisisi pengetahuan menjadi hal yang terlupakan.

Dari sisi keilmuan manajemen, perlu diakui peranan pengetahuan bukan sumber daya utama. Bagaimanapun, sumber daya yang ada perlu dikelola dengan baik dengan prosedur atau inovasi yang terus berkembang. Pengembangan teknologi produk misalnya, tentu tidak dapat dihasilkan jika tidak ada sumber daya manusia terbaik. Manajemen pengetahuan dan keterampilan karyawan itu sendiri yang menjadi sumber utama pengembang teknologi baru, sudah tentu harus menjadi perhatian utama.

Pengetahuan dan keahlian karyawan seharusnya dianggap sebagai sumber daya strategis yang penting dan asset berharga dalam mempertahankan keunggulan kompetitif suatu organisasi. (Bender \& Fish 2000; Wong \& Radcliffe 2000, dalam Martins \& Martins, h. 50). Tidak hanya mengungguli, asset berharga ini bahkan juga dapat mempertahankan keunggulan kompetitif sebuah organisasi.

Lebih jauh menurut Porter, keunggulan kompetitif berakar dari kemampuan organisasi untuk mengeluarkan kekuatan internal untuk merespon peluang dari lingkungan eksternal sambil menghindari ancaman eksternal dan kelemahan internal. Kekuatan yang dimiliki oleh organisasi bisa berasal dari berbagai hal. Kerangka yang bisa digunakan untuk menilai keunggulan kompetitif adalah dengan mengkaji analisis SWOT.

Jika dikaji lebih jauh, keunggulan kompetitif pada akhirnya memang dikaitkan dengan kepemilikan sumber daya berharga yang memungkinkan perusahaan untuk melakukan kegiatan yang lebih baik atau lebih murah dibandingkan competitor (Collis, Montgomery 1995, h. 120). Sumber daya berharga seperti pengetahuan merupakan salah satu keunggulan kopetitif yang dimiliki oleh perusahaan seharusnya lebih baik dari kompetitornya. Namun, bukan hanya pengetahuan yang lebih baik, tapi juga 
mengelola pengetahuan lebih baik dari Penciptaan Pengetahuan

kompetitor.

Pengetahuan yang terakumulasi dari luar dibagi secara luas dalam organisasi, disimpan sebagai bagian dari basis pengetahuan perusahaan, dan dimanfaatkan oleh mereka yang terlibat dalam pengembangan teknologi baru dan produk (Nonaka dan Takeuchi 1995, h. 6). Tidak hanya bagi yang terlibat dalam pengembangan teknologi baru atau produk, basis pengetahuan perusahaan ini dapat dimanfaatkan oleh seluruh elemen dalam sebuah organisasi atau perusahaan.

Konversi terjadi, proses percakan dari luas ke dalam dan kembali ke luar lagi dalam bentuk produk baru, layanan, atau sistem. Inovasi yang berkelanjutan, pada gilirannya, menyebabkan keunggulan kompetitif, seperti yang ditujukan pada gambar berikut ini.

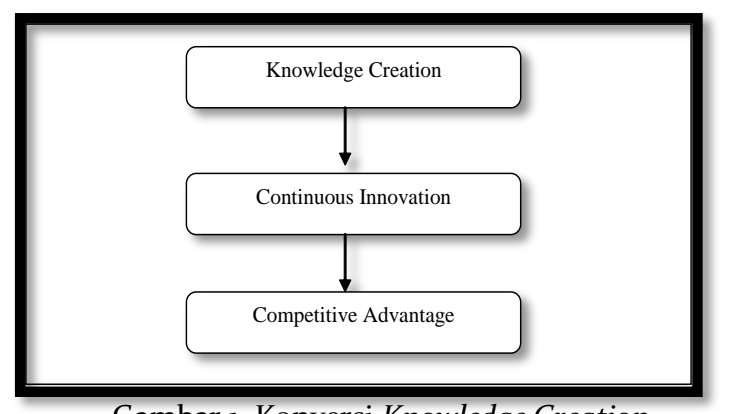

Gambar 1. Konversi Knowledge Creation

Dapat dilihat dari gambar di atas keunggulan kompetitif berasal dari proses yang terus menerus dari penciptaan pengetahuan dan inovasi yang berkelanjutan. Langkahlangkah inilah yang diambil oleh perusahaanperusahaan besar Jepang seperti Honda, Matsushita. Langkah ini diambil untuk menciptakan inovasi yang dinamis oleh perusahaan-perusahaan tersebut, dan menjadi pembeda dengan perusahaan-perusahaan kompetitor lainnya. Tidak salah, jika perusahaan tersebut dapat berkembang pesat dan menjadi perusahaan unggulan.

Pada pembahasan selanjutnya akan digambarkan bagaimana penciptaan pengetahuan dan inovasi berkelanjutan membuahkan keunggulan kompetitif bagi organisasi atau perusahaan.
Penciptaan pengetahuan pada dasarnya dapat dilihat dari dua dimensi. Sebagaimana yang dikemukakan Nonaka dan Takeuchi (1995, h.59-6o), penciptaan pengetahuan dapat dilihat dari dimensi ontologi dan dimensi epistimologi. Dari dimensi ontologi, pengetahuan digambarkan sebagai sesuatu yang diciptakan hanya oleh individual-individual. Tugas organisasi adalah mendukung individual yang ada dalam organisasi tersebut dan menyediakan konteks agar mereka dapat mencipta pengetahuan. Penciptaan pengetahuan oleh individu-individu dilakukan dengan mengkristalisasinya sebagai bagian dari jaringan pengetahuan organisasi.

Sedangkan dari dimensi epistimologi, penciptaan pengetahuan itu sendiri berasal dari pengetahuan tacit dan eksplisit. Pengetahuan tacit bersifat personal, spesifik pada konteks, dengan demikian menjadi sulit untuk diformalisasi dan dikomunikasikan kembali. Sedangkan pengetahuan eksprilist di sisi lain, merujuk pada pengetahuan yang dapat dipindahkan secara formal, dengan bahasa yang sistematik.

Ada berbagai model dalam proses penciptaan pengetahuan. Salah satu model yang terintegrasi adalah Five Phase Model of the Organizational Knowledge Creation Process, yang digambarkan pada gambar 2.

Model ini menggambarkan proses berbagi pengetahuan tacit menjadi hal yang krusial dilakukan pada fase pertama. Dilanjutkan dengan fase kedua, mencipta konsep dan pembenarannya, yang pada dasarnya penentuan apakah konsep yang baru tersebut benar-benar tepat untuk organisasi. Lalu pada fase keempat, dimulailah langkah untuk membangun pola dasar, semacam prototype atau mekanisme operasi. Dan pada fase terakhir, fase yang kadang dilupakan, yaitu memperluas pengetahuan yang sudah diciptakan. Perluasan dapat dilakukan ke inter divisi, antar divisi, atau bahkan ke luar 


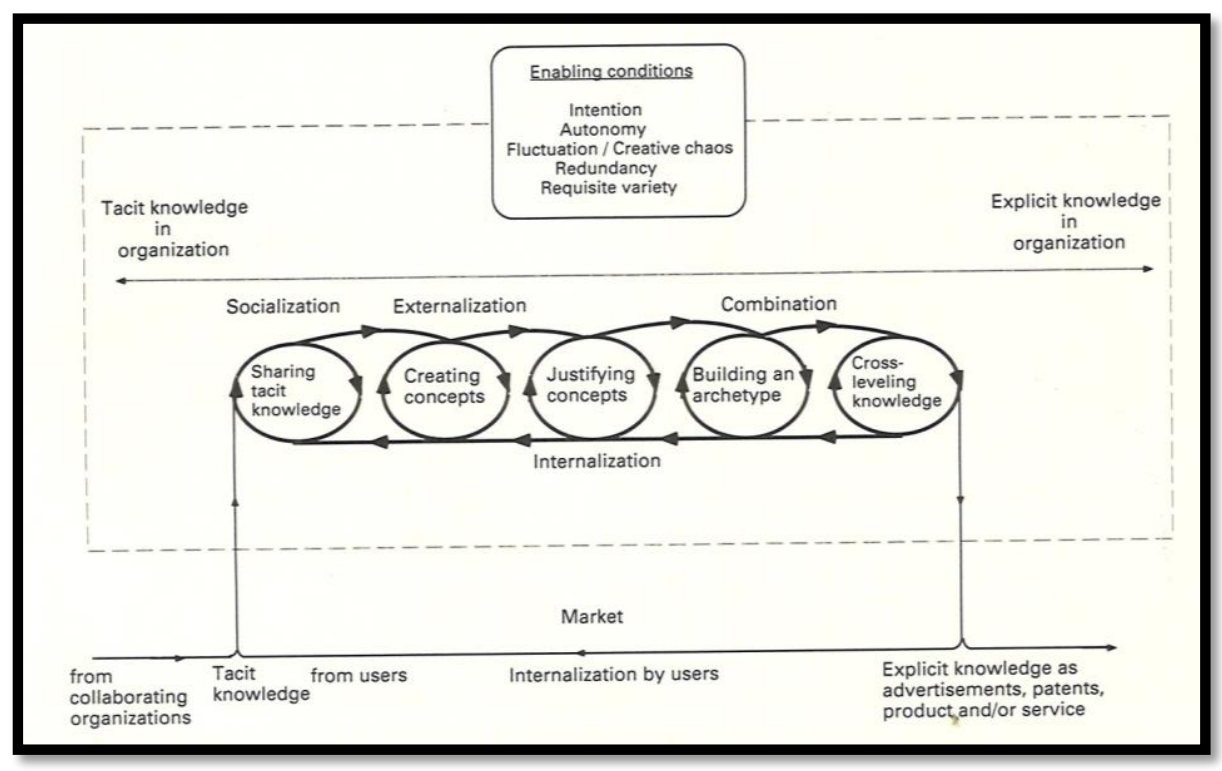

Gambar 2. Five Phase Model of the Organizational Knowledge Creation Process

perusahaan atau organisasi, seperti consumer, perusahaan afiliasi, universitas, atau distributor.

Proses penciptaan ini tidak berhenti dalam satu fase, sebagaimana digambarkan pada gambar fase di atas, setelah pengetahuan eksplisit ini sudah dipatenkan dan menjadi produk dan atau pelayanan yang diberikan perusahaan, maka proses internalisasi oleh pasar mulai terjadi. Pada akhirnya masukan dari pasar menjadi penggerak proses pertama dimulai kembali, yaiu berbagi pengetahuan tacit. Inovasi yang berkelanjutan juga tidak terlepas dari proses penciptaan pengetahuan. Karena proses penciptaan ini tidak berhenti pada satu fase saja selalu berkelanjutan mencipta pengetahuan dan inovasi baru di perusahaan, begitu seterusnya.

Pada akhirnya pasarlah yang menentukan perbedaan antara perusahaan yang satu dengan yang lain, dengan inovasi yang berkelanjutan dan produk-produk baru yang mereka rasakan. Inilah yang menjadi keunggulan kompetitif perusahaan tersebut.

\section{PEMBAHASAN}

\section{Sumber Daya Manusia sebagai Basis Keunggulan Kompetitif BTPN Syariah}

BTPN Syariah yang dulunya merupakan Unit Usaha Syariah bagian dari BTPN, terpisah dan merger dengan Bank Sahabat Purbadanarta pada 14 Juli 2014. Bisnis BTPN Syariah saat menjadi Unit Usaha Syariah BTPN sudah berkembang cukup pesat. Sehingga ketika berdiri sendiri di 2014, BTPN Syariah sudah memiliki hampir 1,04 juta nasabah (Laporan Tahunan BTPN Syariah 2014, h.88), dengan jaringan kantor yang cukup luas. Dengan jumlah aset 3,7T di akhir 2014 dan meningkat menjadi 9,2T di akhir 2017. Kinerja sehat BTPN Syariah juga terlihat dari meningkatnya laba di setiap tahunnya. Berbagai indikator menunjukkan sehatnya kondisi BTPN Syariah.

Semua perkembangan yang ada tersebut tidak terlepas dari peranan sumber daya manusia yang terlibat di dalamnya. Sebagaimana yang sudah diuraikan di atas, pengetahuan dan keahlian yang dimiliki oleh karyawan BTPN Syariah seharusnya dianggap sebagai sumber daya strategis yang sangat penting. Tidak hanya itu, pengetahuan dan keahlian yang dimiliki juga sebagai asset berharga dalam mempertahankan keunggulan kompetitif BTPN Syariah.

Saat ini BTPN Syariah melayani segmen pasar terbesar, yaitu segmen masyarakat berpenghasilan rendah dan segmen usaha mikro dan kecil. Dengan produk utama berupa Pembiayaan, BTPN Syariah menyasar wanita pra sejahtera produktif untuk meningkatkan kesejahteraannya melalui modal usaha. Selain produk utama tersebut, pasar yang demikian besar mulai tersentuh inovasi-inovasi baru dari BTPN Syariah seperti pocket banking, yang disebut sebagai BTPN WOW! Syariah. Transaksi perbankan nasabah tidak lagi terbatas 
dilakukan hanya di Kantor Cabang melainkan melalui ponsel. Masyarakat di pedesaan atau perkampungan dapat melakukan transaksi perbankan tunai melalui Agen BTPN WOW! Syariah yang tersebar di wilayah-wilayah terpencil di Indonesia.

Inovasi demi inovasi terus berkembang di BTPN Syariah. Sedemikian besar asset yang dimiliki oleh BTPN Syariah, tidak hanya produk yang dimunculkan, tetapi inovasi yang berkelanjutan dibangun oleh sumber daya manusianya. Karyawan BTPN Syariah dengan pendekatan uniknya kepada nasabah menjadi tonggak penting pelayanan di garda terdepan bisnis BTPN Syariah. Pengembangan inovasi berkelanjutan ini membutuhkan basis knowledge management yang sangat kuat untuk mensupport karyawan dengan baik.

\section{Manajemen Pengetahuan dalam Meningkatkan Keunggulan Kompetitif}

Berbagai literatur sudah cukup banyak membahas bagaimana manajemen pengetahuan memberikan sumbangan yang cukup besar dalam meningkatkan keunggulan kompetitif. Salah satunya penelitian oleh Englis, dkk (2005, h. 91-102) yang membandingkan antara perusahaan kecil dan perusahaan besar dalam mengelola pengetahuannya. Hasil penelitiannya menemukan bahwa perusahaan besar berbeda cukup signifikan dari perusahaan kecil dalam mengelola pengetahuan, baik secara internal maupun eksternal. Perusahaan besar telah mengelola sistem memori untuk organisasi mereka, sementara perusahaan kecil menyebarkan memori organisasi atau berbagi informasi kepada seluruh karyawan yang ada, dengan cara yang lebih sederhana.

Manajemen pengetahuan sendiri dapat dilakukan dengan beberapa pendekatan, antara lain seperti Pendekatan Informasi dan Teknologi atau Pendekatan Sumber Daya Manusia. Berdasarkan pendekatan informasi dan teknologi, pengetahuan distandarkan, disimpan, dan didistribusi dengan bantuan teknologi informasi. Pengetahuan itu sendiri disimpan menggunakan software. Sedangkan pendekatan sumber daya manusia, manajemen pengetahuan dipandang sebagai proses sosial dalam mencipta dan berbagi pengetahuan melalui percakapan. Berfokus pada hubungan, budaya kolaborasi berbagi pengetahuan antar level atau tim. Pengetahuan dapat dipahami hanya pada konteks interaktivitas dan komunikasi satu sama lain.

Pengetahuan yang telah diciptakan harus dikelola dengan baik. Apapun pendekatan yang digunakan dalam mengelola pengetahuan, dapat dipastikan pengetahuan yang ada dalam sebuah perusahaan dapat tersimpan dengan baik dan dapat dimanfaatkan untuk inovasi dan pengembangan yang berkelanjutan.

Selain itu, perlu diketahui bahwa tiap organisasi memiliki beberapa sumber daya manusia kunci yang pengetahuannya sangat krusial dan penting untuk keberlangsungan organisasi. Bill Gates bahkan pernah berkomentar, jika 20 orang kunci di Microsoft pergi, maka perusahaannya akan beresiko bangkrut (Bahra 2001). Begitu pula dalam dunia perbankan, yang memiliki cukup banyak orang kunci yang memiliki pengalaman banyak dan sangat berpengaruh dalam perusahaan.

Saat ini BTPN Syariah memiliki beberapa orang kunci yang diidentifikasi melalui analisis Talent Management di Divisi Human Capital BTPN Syariah. Cara terbaik untuk mempertahankan pengetahuan meraka adalah dengan mengelola pengetahuan yang mereka miliki. Pengalaman dan pengetahuan yang dimiliki oleh karyawan kunci BTPN Syariah tersebut tentunya harus didokumentasikan dengan baik.

\section{SIMPULAN}

Manajemen pengetahuan dipercayai sebagai kunci keberhasilan perusahaan dengan menciptakan pengetahuan dan inovasi baru dan berkelanjutan. Berbasis SDM unggul yang berada di dalamnya, BTPN Syariah dapat mengembangkan inovasi baru dan berkelanjutan. Saat ini sudah saatnya BTPN Syariah mulai mengelola pengetahuan yang ada dengan manajemen pengetahuan yang baik. Apapun pendekatan yang digunakan dalam mengelola pengetahuan, tentunya dapat membantu agar asset berharga tersebut dapat meningkatkan keunggulan kompetitif BTPN Syariah. Transformasi terus menerus melibatkan kedinamisan, interaktif, dan proses yang simultan, tentunya berbuah keunggulan kompetitif. 


\section{UCAPAN TERIMA KASIH}

Terima kasih kepada management BTPN Syariah, khususnya Departemen HC Learning \& Talent Management yang berkenan menjadi subyek penelitian ini.

\section{DAFTAR PUSTAKA}

Bahra, N. (2001). Competitive Knowledge Management. Houndmills: Palgrave.

Bhagat, R.S., Kedia, B.L., Harveston, P., and Triandis, H.C. (2002). Cultural variations in the crossborder transfer of organizational knowledge: An integrative framework. Academy of Management Review, 27 (2).

Collis, D. J., \& Montgomery, C. A., 1995. Competing on resources: Strategy in the 1990s. Harvard Business Review, 23.

Danskin, P., Englis, B.G., Solomon, M.R., Goldsmith, M. \& Dave, R., 2005. 'Knowledge management as competitive advantage: Lessons from the textile and apparel value chain', Journal of Knowledge Management.

Hamel dan Prahalad dalam Longenecker, Clinton $\mathrm{O}$;Ariss, Sonny S, 2002. Creating competitive advantage through effective management education. The Journal of Management Development; 2002; 21, 9/10; ProQuest.

Hitt, M. A., Ireland, R. D., and Lee, H., 2000. Technological learning, knowledge management, firm growth and performance: an introductory essay. Journal of Engineering and Technology Management, 17.

Martins, E.C. \& N. Martins. (2011). The role of organisational factors in combating tacit knowledge loss in organizations, Southern African Business Review Volume 15 Number 12011.

Mooney, Ann. (2007). Journal Education for Business. November/December, New Jersey: Heldref Publication.

Nonaka, Ikujiro dan Hirotaka Takeuchi, (1995). The Knowledge-Creating Company, How Japanese Companies Create the Dynamics of Innovation. Oxford University Press.

Porter, M., (1985). Competitive advantage. Boston, MA: Free Press.

Shehabat, Issa, Saad A. Mahdi, and Kamel Khoualdi, (2008). E-Learning as a Knowledge Management Approach for Intellectual Capital Utilization. Turkish Online Journal of Distance Education-TOJDE, Vol. 9 Number 1 Article 14.

The Body Shop International - Our Values and Campaigns dalam Dyah Puji Kusumawati, (2009) Pengaruh Cause Related. 